\title{
Atorvastatin Protects Myocardium Against Ischemia-Reperfusion Injury Through Inhibiting miR-199a-5p
}

\author{
YaBei Zuo ${ }^{\mathrm{a}}$ YuZhao Wang ${ }^{\mathrm{b}}$ HaiJuan $\mathrm{Hu}^{\mathrm{a}}$ Wei Cui ${ }^{\mathrm{a}}$ \\ a Department of Cardiology, Second Hospital of Hebei Medical University, Shijiazhuang, ${ }^{b}$ Department of \\ Radiology, Second Hospital of Hebei Medical University, Shijiazhuang, Hebei, China
}

\section{Key Words}

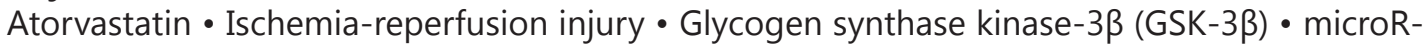
$N A \cdot \operatorname{miR}-199 a-5 p$

\begin{abstract}
Objective: This study aimed to evaluate the protective effects of atorvastatin against myocardial ischemia/reperfusion (I/R) injury in cardiomyocytes and its possible underlying mechanism. Method: Direct cytotoxic effect of OGD/R on cardiomyocytes with and without atorvastatin pretreatment was evaluated. Effects of atorvastatin on expression of GSK-3 $\beta$ and miR-199a$5 p$ were determined using RT-PCR and Western blot. In addition, GSK-3 $\beta$ expression with miR-199a-5p upregulation and downregulation was detected using RT-PCR, Western blot, and immunohistochemistry. Results: Pretreatment with atorvastatin significantly improved the recovery of cells viability from OGD/R $(p<0.05)$. In addition, the atorvastatin pretreatment significantly increased GSK-3 $\beta$ expression both in mRNA level and protein level and decreased miR-199a-5p expression in mRNA level $(p<0.05)$. Upregulation and downregulation of miR-199a-5p respectively decreased and increased GSK-3 $\beta$ expression both in mRNA level and protein level. Conclusion: These results suggested that atorvastatin provides the cardioprotective effects against I/R injury via increasing GSK-3 $\beta$ through inhibition of miR199a-5p.
\end{abstract}

\section{Introduction}

Percutaneous coronary intervention (PCI) is a critical part of the intervention of acute myocardial infarction (AMI) patients [1]. However, myocardial tissue suffers from myocardial ischemia/reperfusion (I/R) injury during revascularization, which results in poor clinical outcomes [2]. Apoptosis of cardiomyocytes is known to be an important mechanism of

Y. Zuo, and Y. Wang contributed equally.

\begin{tabular}{ll}
\hline Wei Cui & Department of Cardiology, Second Hospital of Hebei Medical University, No. 215 \\
& Heping West Road, Shijiazhuang, Hebei 050000 (PR China) \\
& Tel. +86-311-6600-2115, Fax +86-311-6600-2115, E-Mail cuiwei@medmail.com.cn
\end{tabular}


I/R injury [3-5]. Accumulating evidence has shown that apoptosis of cardiomyocytes is

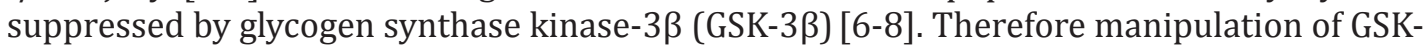
$3 \beta$ is a promising strategy for myocardial protection in I/R injury. The GSK-3 family of serine/ threonine kinases plays an important role in various pathologic processes of heart, including pressure overload and ischemic injury. It is comprised of two isoforms ( $\alpha$ and $\beta$ ) which are encoded by distinct genes and are ubiquitously expressed. Numerous studies have shown that GSK-3 $\beta$, but not GSK-3 $\alpha$ is cardioprotective [9-10].

MicroRNAs regulate gene expression at the posttranscriptional level by degrading or blocking translation of target messenger RNA (mRNA) $[11,12]$. Various studies have shown that increased miR-199a-5p expression is responsible for pathophysiological alterations contributing to and promoting the development of heart diseases including atrial fibrillation and heart failure $[13,14]$. Therefore, therapeutic interventions targeting miR-199a-5p represent promising strategies for the treatment of I/R injury. Statins were found to prevent heart failure, acute coronary syndrome (ACS), and cardiovascular risk [15-17]. Numerous studies have demonstrated the cardioprotection against myocardial I/R injury of statins in animal experiments and clinical studies $[18,19]$. However, the major molecular mechanisms of the cardioprotective effect of statins have not been completely elucidated. Therefore, we hypothesized that cardioprotection by statins may be associated with inhibition of apoptosis in myocardial I/R injury through miR-199a-5p /GSK-3 $\beta$ pathway.

This work examined the effects of atorvastatin on H9c2 cardiomyoblast cells and neonatal rat cardiac ventricular cardiomyocytes by detecting changes in the mRNA and protein expression levels of GSK-3 $\beta$. Moreover, we firstly observed the influence of atorvastatin on miR-199a-5p expression and its influence on GSK-3 $\beta$ expression. We further analyzed the mechanism involved in the effects of atorvastatin on myocardial I/R injury to provide a theoretical basis and new intervention targets for the prevention and treatment of myocardial I/R injury in the clinic.

\section{Materials and Methods}

\section{Drugs and reagents}

Atorvastatin and $\mathrm{LiCl}$ were purchased from Sigma-Aldrich Corp. Antibodies for GSK-3ß, Caspase 9 and Bcl-2 were provided by BD Biosciences. Antibody for Cytochrome $\mathrm{C}$ was from Abcam. Antibodies for $\alpha$-actin, $\beta$-actin and GAPDH were provided by Sigma. LY294002 was purchased from Cayman Chemical. Syn-rno-miR-199a-5p miScript miRNA Mimic, anti-rno-miR-199a-5p miScript miRNA Inhibitor, AllStars Negative Control siRNA, AllStars Mm/Rn Cell Death Control siRNA, and HiPerFect Transfection Reagent was purchased from QIAGEN. 3-(4,5-dimethylthiazol-2-yl)-5-(3-carboxymethoxyphenyl)-2-(4-sulfophenyl)-2Htetrazolium (MTS) was purchased from Promega.

\section{Cell culture and treatment}

Neonatal rat cardiac ventricular cardiomyocytes were prepared from 1 to 3 day-old neonatal SD rat and cultured as previously described $[20,21]$. The cells were maintained in a humidified incubator $\left(37^{\circ} \mathrm{C}\right.$ with $\left.5 \% \mathrm{CO}_{2}\right)$. Brdu $(0.1 \mathrm{mM})$ was added to the medium for the first 2 days to inhibit fibroblast growth. Neonatal rat myocytes were cultured to $70 \%$ confluence and then serum starved in basal medium (DMEM) for $24 \mathrm{~h}$ before the drug treatment. H9c2 rat myocardial cells (ATCC CRL 1446) were cultured in DMEM supplemented with 10\% FBS (Hyclone), penicillin G (100 U.mL $\left.L^{-1}\right)$, streptomycin $\left(100 \mu \mathrm{g} \cdot \mathrm{mL}^{-1}\right)$ and glutamine $(2 \mathrm{mM})$. The neonatal rat cardiac ventricular cardiomyocytes and $\mathrm{H} 9 \mathrm{c} 2$ cells were treated with oxygen-glucose deprivation/recovery (OGD/R) with or without pretreatment with as described previously with minor modification [22]. The pretreatment included incubation with $1 \mu \mathrm{M}$ atorvastatin for 3 hours or10 $\mu$ M GSK-3 $\beta$ inhibitor LiCl for 1 hour. Then cells were rinsed twice, incubated in glucose-free DMEM and subsequently placed in an anaerobic chamber containing a mixture of $95 \% \mathrm{~N}_{2}$ and $5 \% \mathrm{CO}_{2}$ at $37^{\circ} \mathrm{C}$ for $6 \mathrm{~h}$. Following OGD, glucose was added to normal levels (final concentration: $4.5 \mathrm{mg} \cdot \mathrm{mL}^{-1}$ ), and cells were incubated under normal growth conditions (95\% air and 5\% $\mathrm{CO}_{2}$ ) for an additional $18 \mathrm{~h}$, as OGD/R, unless otherwise specified. 


\section{Cellular Physiology Cell Physiol Biochem 2016;39:1021-1030 \begin{tabular}{ll|l}
\hline and Biochemistry $10.1159 / 000447809$ & $\begin{array}{l}\text { Published on } 2016 \text { The Author(s). Published by S. Karger AG, Basel } \\
\text { www.karger.com/cpb }\end{array}$ \\
\hline
\end{tabular}

Neonatal rat cardiac ventricular cardiomyocytes identification

After culture for different time periods, the samples were rinsed with PBS, fixed with $4 \%$ paraformaldehyde for $20 \mathrm{~min}$, and then permeabilized with glycine/triton solution (PBS/0.1\% Triton/10 mM glycine). The samples were incubated with mouse monoclonal anti- $\alpha$-actin (1:300 dilution) (cat\# A7811; Sigma) at $4^{\circ} \mathrm{C}$ overnight. After rinses, the samples were then incubated with anti-mouse IgGFITC (1:300 dilution) (cat\# F2012; Sigma) for $60 \mathrm{~min}$ at $37^{\circ} \mathrm{C}$. Nuclei were counter-stained with $100 \mathrm{nM}$ DAPI (Invitrogen) for $30 \mathrm{~min}$ followed by rinses with PBS. Fluorescent images were taken with a spectral confocal microscope imaging system (Leica TCS SP2).

\section{Cell viability assays}

Cell viability was assessed by the CellTiter 96 Aqueous One Cell Proliferation assays (promega). Cells were seeded at $5 \times 10^{3}$ per well in 96-well plates overnight. After the treatment cells were incubated with $20 \mu \mathrm{l} / 100 \mu \mathrm{l}$ MTS for $1 \mathrm{~h}$. Cell viability was determined by measuring the absorbance at $490 \mathrm{~nm}$ using a microplate reader (M200PRO, TECAN, Austria).

\section{Measurement of LDH activity}

A supernatant was obtained from the culture medium by centrifugation for $1 \mathrm{~min}(1000 \mathrm{r} / \mathrm{min})$. The activity of LDH in the supernatant was detected using a commercial kit (Jiancheng, China).

\section{Analysis of GSK-3 $\beta$ mRNA expression}

Total RNA was extracted with TriZol Reagent (Invitrogen, Carlsbad, CA, USA) according to the manufacturer's instructions. The cDNA was synthesized from total RNA $(0.5 \mu \mathrm{g})$ using the Reverse Transcription System (Promega) according to the manufacturer's instructions. Subsequently, the cDNA was subject to real-time polymerase chain reaction (PCR) using GoTaq qPCR Master Mix (Promega). Reactions were performed on a 7500 Real-Time PCR System (Applied Biosystems).The primers used for real-time PCR were as follows: GSK-3 $\beta$ forward 5'- TCCATTCCTTTGGGATCTGCC -3 ' and reverse 5'-ATCAGCTCTGGTGCCCTGTAGTAC -3'; $\beta$-actin forward 5'-CAGGGTGTGATGGTGGG -3' and reverse 5'GGAAGAGGATGCGGCAG-3'. The fold change in expression of each gene was calculated using the $\Delta \Delta \mathrm{Ct}$ method [23].

Analysis of miR-199a-5p expression

Total RNA was extracted with TriZol Reagent (Invitrogen) according to the manufacturer's instructions. qRT-PCR was performed using All-in-One miRNA qRT-PCR Detection Kit (GeneCopoeia). Reactions were performed on a 7500 Real-Time PCR System (Applied Biosystems). The primers used for real-time PCR were as follows: rno-miR-199a-5p and U6 (GeneCopoeia). The fold change in expression each gene was calculated using $\Delta \Delta$ Ct method.

\section{Transfection of $\mathrm{H} 9 \mathrm{c} 2$}

H9c2 cells were seeded in 6-well plates for 12 hours. Before transfection, the medium was replaced with DMEM without serum and antibiotics. The $10 \mathrm{nM}, 20 \mathrm{nM}$, and 50nM AllStars Mm/Rn Cell Death Control siRNA (QIAGEN) were used to incubate for 24 hours, 48 hours, and 72 hours to select the best condition. Transfection efficiency was observed and evaluated under the microscope. Ultimately transfection with $20 \mathrm{nM}$ and was selected due to the highest efficiency which was over $70 \%$. HiPerFect Transfection Reagent (QIAGEN) was used as transfection reagents. $20 \mathrm{nM}$ Syn-rno-miR-199a-5p miScript miRNA Mimic and antirno-miR-199a-5p miScript miRNA Inhibitor were used to respectively overexpress and inhibit miR-199a-5p expression. AllStars Negative Control siRNA was used as negative control.

\section{Western blot analysis}

The proteins were separated by 10\% SDS-PAGE, then transferred onto PVDF membranes and blotted with specific antibodies against GSK-3 $\beta$ (1:2000), caspase 9 (1:2000), BCL-2 (1:2000), cytochrome C (1:5000), GAPDH (1:1000), and $\beta$-actin (1:1000) at $4^{\circ} \mathrm{C}$ overnight, and then incubated with the horseradish peroxidase-conjugated secondary antibody $(1: 5000)$ at $37^{\circ} \mathrm{C}$ for $1 \mathrm{~h}$. They were then processed for chemiluminescent detection according to the manufacturer's instructions (Santa Cruz Biotechnology). All bands were evaluated by densitometry with Quantity One V4.6.2 software (Bio-Rad, Hercules, CA, USA). Bands of interest were normalized against GAPDH and $\beta$-actin. Data are presented as relative density ratios. 


\section{Immunofluorescence assay}

The cells were fixed with $4 \%$ paraformaldehyde for $20 \mathrm{~min}$, and then permeated with glycine/triton solution (PBS/0.1\% Triton/10 mM glycine). The samples were incubated with mouse monoclonal anti-GSK$3 \beta\left(1: 100\right.$ dilution) (BD Biosciences) at $4^{\circ} \mathrm{C}$ overnight. After rinses, the samples were then incubated with anti-mouse IgG-FITC (1:300 dilution) (BD Biosciences) for $40 \mathrm{~min}$ at $37^{\circ} \mathrm{C}$. Nuclei were counter-stained with $100 \mathrm{nM}$ DAPI (Invitrogen) for $30 \mathrm{~min}$ followed by rinses with PBS. Fluorescent images were taken with a spectral confocal microscope imaging system (Leica TCS SP2).

\section{Statistical analysis}

Statistical analysis was performed using SPSS 13.0. The data were expressed as the mean \pm standard deviation (SD). Differences were analyzed by one-way analysis of variance (ANOVA) followed by the Newman-Keuls test; values of $P<0.05$ were considered statistically significant. The $2-\Delta \Delta \mathrm{Ct}$ method was used for the RT-PCR analysis.

\section{Results}

Atorvastatin protects $H 9 c 2$ myocardial cells from $O G D / R$ toxicity by increasing cell viability and decreasing $L D H$ release and expression of Caspase 9, Bcl-2, and Cyto $C$

To evaluate whether atorvastatin protects $\mathrm{H} 9 \mathrm{c} 2$ myocardial cells from $\mathrm{OGD} / \mathrm{R}$, we examined the direct cytotoxic effect of OGD/R on H9c2 cells with and without atorvastatin pretreatment. The data shown in Fig.1A indicates that atorvastatin protects against OGD/R. The cell viability was significantly decreased after OGD/R compared to the control group $(\mathrm{p}<0.05)$. As shown in Fig. 1A, B, and C, pretreatment with atorvastatin increased cell viability and reduced OGD/R-induced LDH release and cell damage-related proteins including Caspase 9, Bcl-2, and Cyto C.

\section{Atorvastatin increases GSK-3 $\beta$ and miR-199a-5p expression of H9c2 myocardial cells}

We further examined the effect of OGD/R on GSK-3 $\beta$ and miR-199a-5p expressions of H9c2 cells with and without atorvastatin pretreatment. As shown in Fig. $2 \mathrm{~A}$ and C, the GSK$3 \beta$ mRNA and protein expression levels were significantly decreased after OGD/R compared to the control group and normoxia group $(\mathrm{p}<0.05)$. Pretreatment with atorvastatin increased both mRNA and protein expression levels of GSK-3 $\beta$. As shown in Fig. 2B, miR-199a-5p

Fig. 1. Effects of atorvastatin on H9c2 myocardial cell viability, LDH release, and expression of Caspase 9, Bcl-2, and Cyto C. A. Graph showing cell viability in the three groups. B. Graph showing LDH release in the three groups. C. The level of Caspase 9, Bcl-2, and Cyto C proteins in the three groups. * Compared with the control group, $\mathrm{p}<0.05$; \# Compared with the $\mathrm{OGD} / \mathrm{R}$ group, $\mathrm{p}<0.05$.

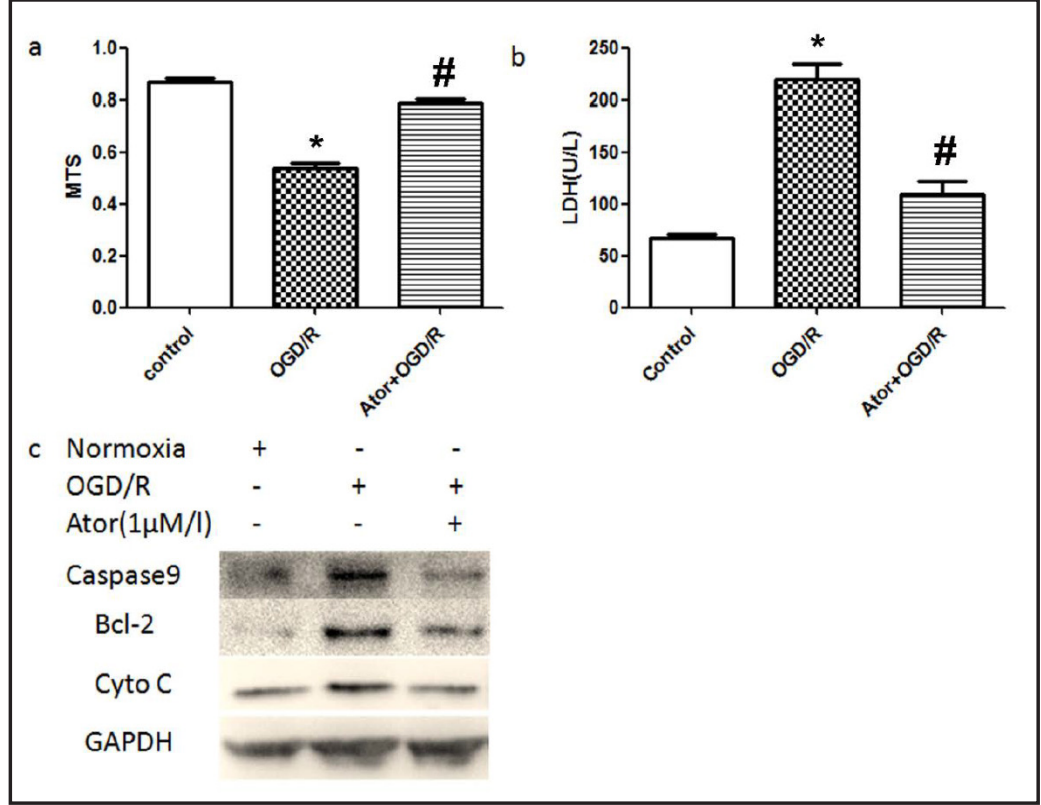


a

C

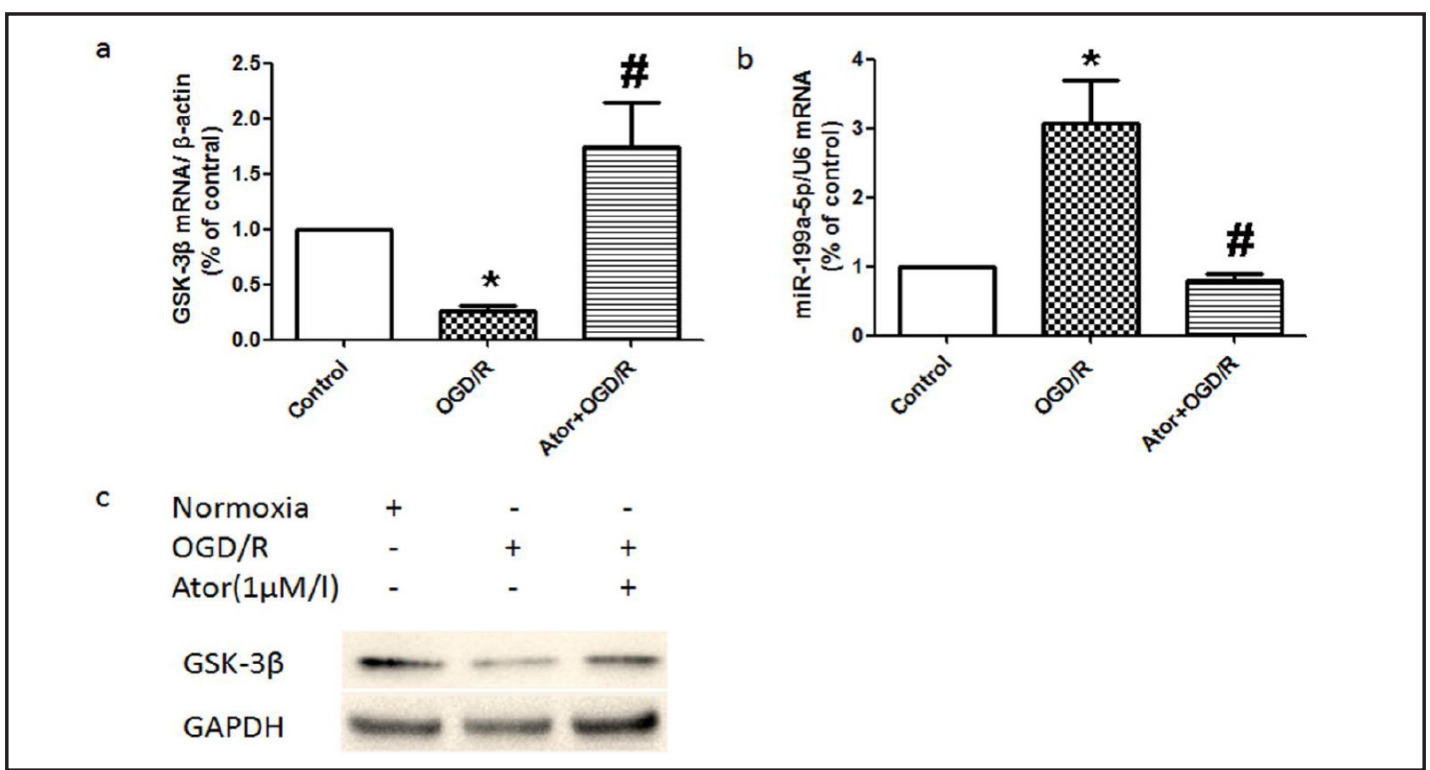

Fig. 2. Effects of atorvastatin on expression of GSK-3 $\beta$ and miR-199a-5p of H9c2 myocardial cells. A. Graph showing GSK-3 $\beta$ mRNA levels in the three groups. B. Graph showing miR-199a-5p mRNA levels in the three groups. C. The level of GSK-3 $\beta$ proteins in the three groups. * Compared with the control group, $\mathrm{p}<0.05$; \# Compared with the OGD/R group, $\mathrm{p}<0.05$.

Fig. 3. The protective effects of atorvastatin on H9c2 myocardial cells through GSK-3 $\beta$. A. Graph showing cell viability in the five groups. B. Graph showing LDH release in the five groups. C. The level of Caspase 9, Bcl-2, and Cyto $\mathrm{C}$ proteins in the five groups. ${ }^{*}$ Compared with the control group, $\mathrm{p}<0.05$; \# Compared with the OGD/R group, $\mathrm{p}<0.05$.

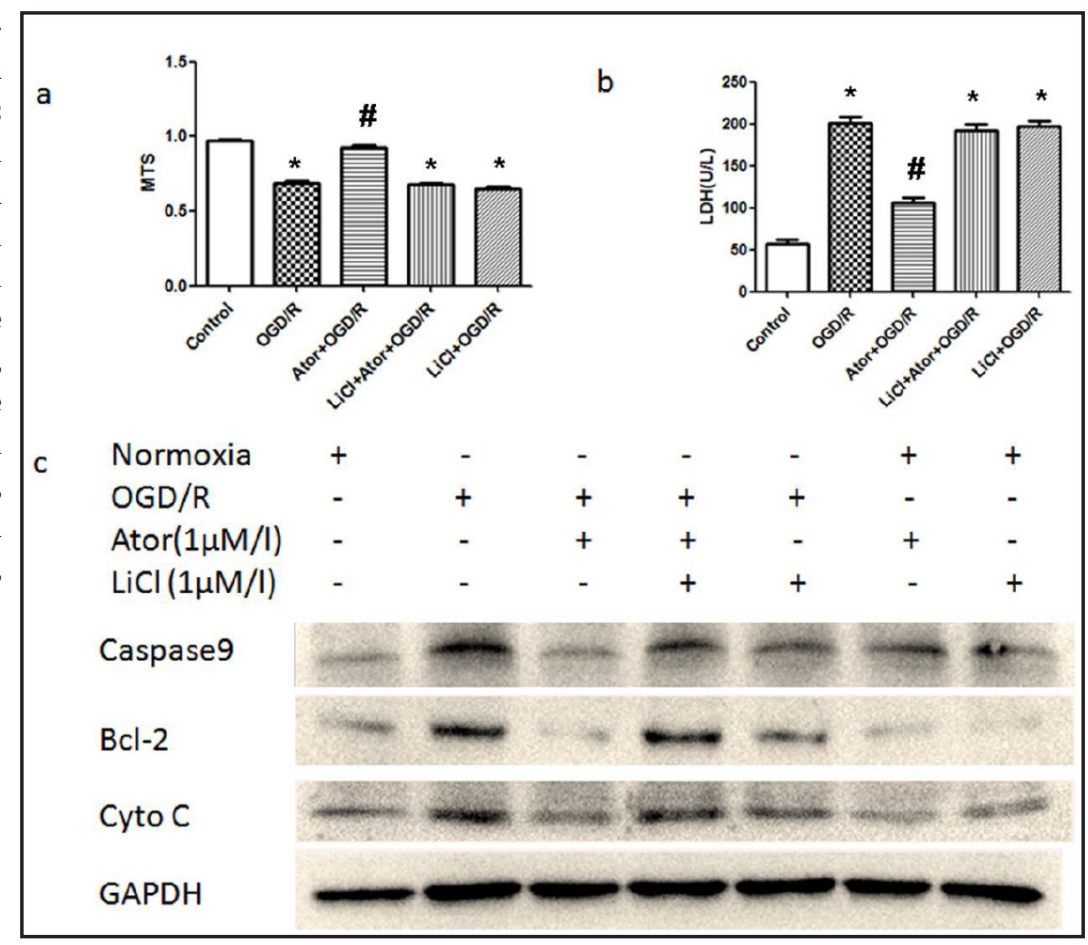

mRNA level was significantly increased after OGD/R ( $<<0.05)$, whereas pretreatment with atorvastatin significantly reserved it $(\mathrm{p}<0.05)$.

Atorvastatin exerts its protective effects against OGD/R through increasing GSK-3 $\beta$ expression

To analyze the exact mechanism of atorvastatin protecting $\mathrm{H} 9 \mathrm{c} 2$ cardiomyoblast cells from OGD/R, we examined the effect of GSK-3 $\beta$ inhibitor LiCl on $\mathrm{H} 9 \mathrm{c} 2$ cells with and without atorvastatin pretreatment. As shown in Fig. 3A, the cell viability was significantly decreased 
Fig. 4. Effects of miR$199 \mathrm{a}-5 \mathrm{p}$ on GSK-3 $\beta$ expression. A. Graph showing GSK-3 $\beta$ mRNA level in the four groups. B. Graph showing miR199a-5p mRNA level after transfection. C. The level of GSK-3 $\beta$ proteins in the three groups. ** Compared with the control group, $\mathrm{p}<0.01$.
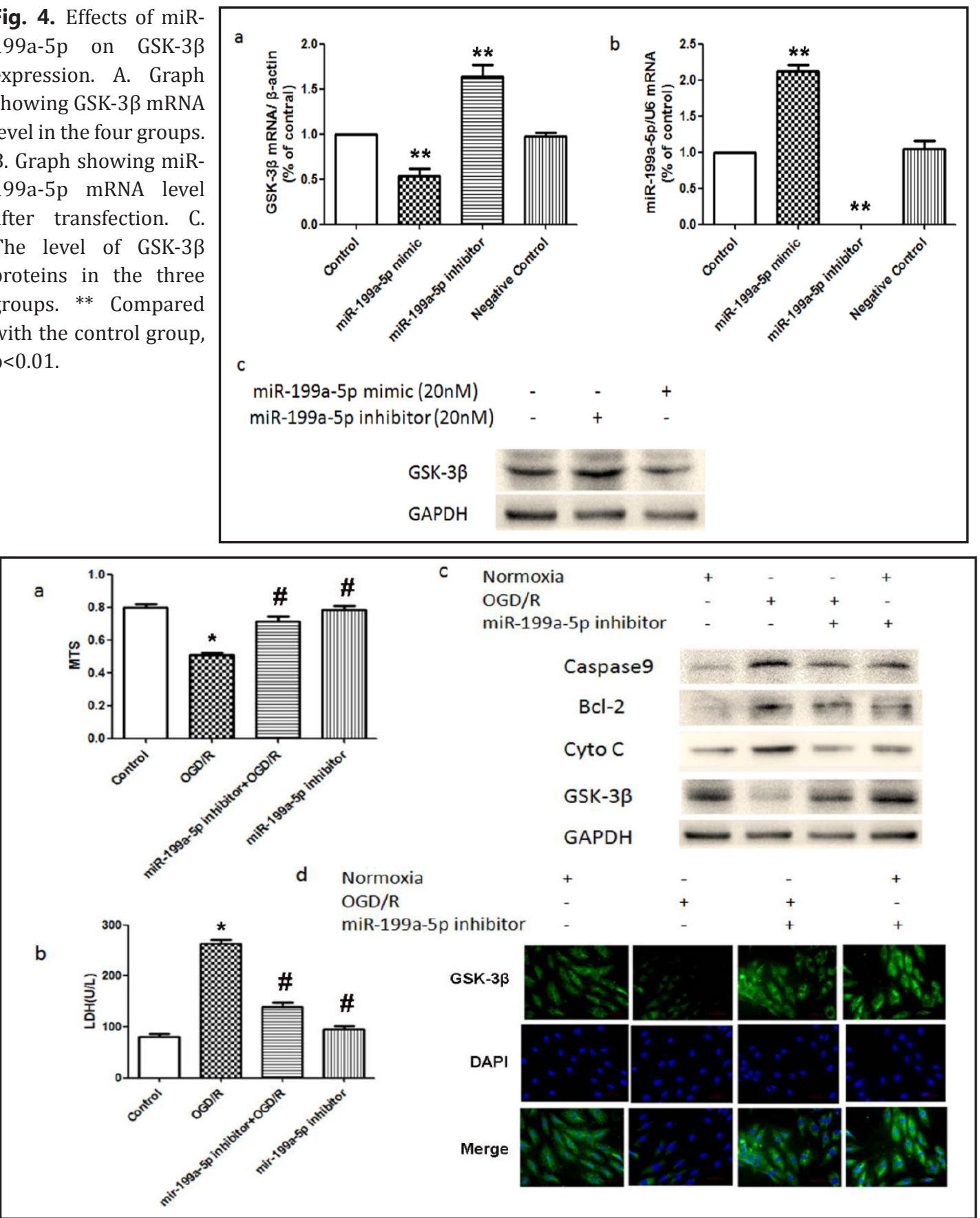

Fig. 5. Effects of miR-199a-5p inhibitor on H9c2 myocardial cells viability, LDH release, and expression of Caspase 9, Bcl-2, and Cyto C. A. Graph showing cell viability in the four groups. B. Graph showing LDH release in the four groups. C. The level of Caspase 9, Bcl-2, Cyto C, and GSK-3 $\beta$ proteins in the four groups. D. Immunohistochemical images showing GSK-3 $\beta$ expression in the four groups. ${ }^{*}$ Compared with the control group, $\mathrm{p}<0.05$. \# Compared with the OGD/R group, $\mathrm{p}<0.05$.

in $\mathrm{LiCl}+$ atorvastatin + OGD/R group compared to the control group $(\mathrm{p}<0.05)$. As shown in Fig. 3B and C, pretreatment with LiCl significantly increased atorvastatin-inhibited LDH release and cell damage-related proteins including Caspase 9, Bcl-2, and Cyto C compared to the control group $(\mathrm{p}<0.05)$.

\section{KARGER}




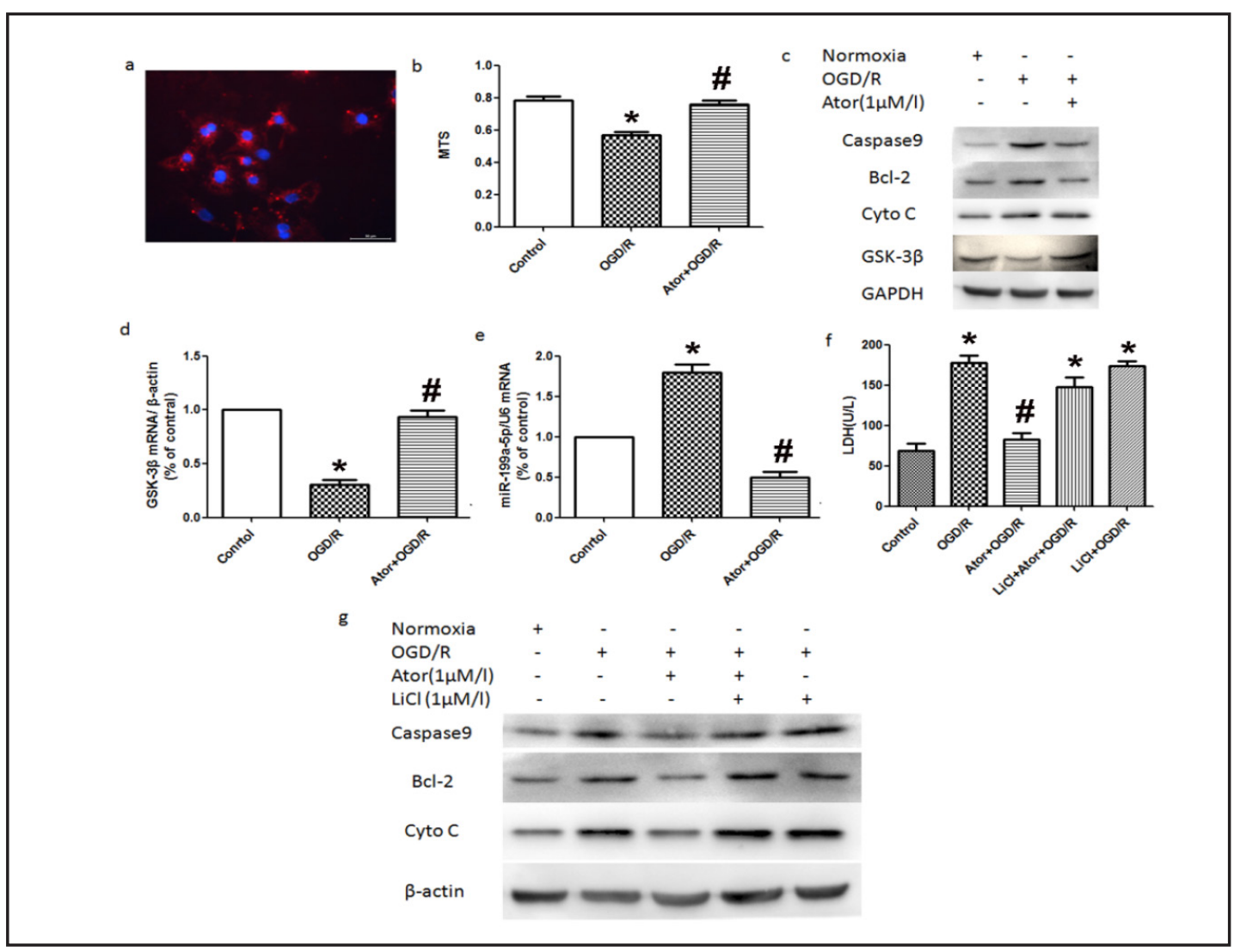

Fig. 6. Effects of miR-199a-5p inhibitor on H9c2 myocardial cells viability, LDH release, and expression of Caspase 9, Bcl-2, and Cyto C. A. Graph showing cell viability in the four groups. B. Graph showing LDH release in the four groups. C. The level of Caspase 9, Bcl-2, Cyto C, and GSK-3 $\beta$ proteins in the four groups. D. Immunohistochemical images showing GSK-3 $\beta$ expression in the four groups. * Compared with the control group, $\mathrm{p}<0.05$. \# Compared with the OGD/R group, $\mathrm{p}<0.05$.

Upregulation and downregulation of miR-199a-5p respectively decreased and increased GSK-3 $\beta$ expression

To evaluate the effect of miR-199a-5p on GSK-3 $\beta$ expression, we examined the effects of miR-199a-5p mimic and inhibitor transfections on GSK-3 $\beta$ expression. As shown in Fig. 4A and $C$, the miR-199a-5p mimic transfection significantly decreased GSK-3 $\beta$ expression both in mRNA and protein levels, while the miR-199a-5p inhibitor transfection increased them $(\mathrm{p}<0.01)$.

Downregulation of miR-199a-5p protects $H 9 c 2$ myocardial cells from OGD/R by increasing cells viability and decreasing LDH release and expression of Caspase 9, Bcl-2, and Cyto C

To evaluate whether miR-199a-5p inhibitor protects H9c2 cardiomyoblast cells from OGD/R, we examined the direct cytotoxic effect of OGD/R on H9c2 cells with and without miR-199a-5p inhibitor pretreatment. As shown in Fig. 5A, B, and C, pretreatment with miR199a-5p inhibitor increased cell viability and reduced OGD/R-induced LDH release and cell damage-related proteins including Caspase 9, Bcl-2, and Cyto C.

Atorvastatin protects neonatal rat cardiac ventricular cardiomyocytes from $O G D / R$ by increasing cell viability and decreasing LDH release and expression of Caspase 9, Bcl-2, and Cyto $C$ via increasing GSK-3 $\beta$

To evaluate whether atorvastatin protects neonatal rat cardiac ventricular cardiomyocytes from $\mathrm{OGD} / \mathrm{R}$ as it does for $\mathrm{H} 9 \mathrm{c} 2$ myocardial cells, we first verified neonatal 


\section{Cellular Physiology Cell Physiol Biochem 2016;39:1021-1030

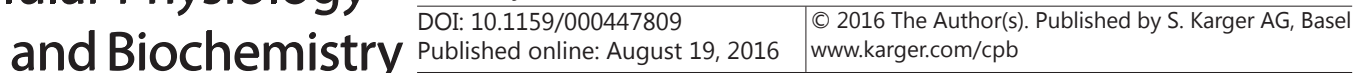 \\ Zuo et al.: Atorvastatin Protects Myocardium}

rat cardiac ventricular cardiomyocytes (Fig. 6A). Then we examined the direct cytotoxic effect of $\mathrm{OGD} / \mathrm{R}$ on neonatal rat cardiac ventricular cardiomyocytes with and without atorvastatin pretreatment. The data shown in Fig. 6B indicates that atorvastatin protects against $\mathrm{OGD} / \mathrm{R}$. The cell viability was significantly decreased after OGD/R compared to the control group $(\mathrm{p}<0.05)$. As shown in Fig. $6 \mathrm{~B}$ and $\mathrm{C}$, pretreatment with atorvastatin increased cell viability and reduced OGD/R-induced cell damage-related proteins including Caspase 9, Bcl-2, and Cyto C. As shown in H9c2 myocardial cells, the protective effects of atorvastatin were through miR-199a-5p /GSK-3 $\beta$ pathway as well (Fig. 6D, E, F, and G).

\section{Discussion}

Apoptosis is a vital pathophysiological mechanism associated with myocardial I/R injury. Prevention and treatment of myocardial apoptosis are an important area of research in myocardial infarction. It was previously reported that atorvastatin could protect vascular smooth muscle cells from TGF- $\beta 1$-stimulated calcification by inducing autophagy via suppression of the $\beta$-catenin pathway [24]. We found that atorvastatin protected cardiomyocytes from apoptosis caused by OGD/R. In our study, cardiomyocytes showed high level of apoptosis after OGD/R which was significantly attenuated by atorvastatin pretreatment, suggesting that attenuation of apoptosis may be the mechanism that enables atorvastatin to protect against myocardial I/R injury.

Furthermore, this study suggests that GSK-3 $\beta$ may be involved in the cardioprotective mechanism of atorvastatin on myocardial I/R injury. GSK-3 $\beta$, a serine/threonine kinase, participates in various cell activities through phosphorylation of the substrate protein [25]. GSK-3 $\beta$ has received increasing attention because of its involvement in some serious diseases including neurological disease, cancer, and I/R injury. In the cardiovascular system, GSK-3 $\beta$ has major roles in glucose metabolism, cardiomyocyte hypertrophy [26], and cell death [27]. Our data shows that the mRNA and protein levels of GSK-3 $\beta$ were decreased by $\mathrm{OGD} / \mathrm{R}$, whereas atorvastatin pretreatment reversed these effects. This finding is consistent with previous reports demonstrating downregulation of GSK-3 $\beta$ in response to I/R injury.

MicroRNAs (miRNAs) are small (-22 nucleotides) non-coding RNAs that regulate gene expression and play an important role in numerous cardiovascular diseases [28]. They function as endogenous intracellular regulators of mRNA translation. Although the significance of miR-199a-5p in myocardial I/R injury has not been studied, it is recognized as a hypoxia-sensitive miRNA [29]. Therefore we speculate that the anti-apoptotic mechanism of atorvastatin may be responsible for the downregulation of miR-199a-5p. We found that GSK$3 \beta$ was decreased in the miR-199a-5p mimic transfection group, whereas it was increased in the miR-199a-5p inhibitor transfection group. Therefore, we believe that downregulation of miR-199a-5p contributes to the cardioprotective effect of atorvastatin against myocardial I/R injury.

To our knowledge, this is the first study showing that atorvastatin pretreatment alters GSK-3 $\beta$ via miR-199a-5p after OGD/R, which raises the possibility that atorvastatin protects myocardium from I/R injury through modulating miR-199a-5p. Wang $\mathrm{H}$ et al. [30] showed that inhibition of miR-199a-5p reduces the replication of HCV via regulating the pro-survival pathway. Sun L et al. [31] showed that inhibition of miR-199a-5p reduced cell proliferation in autosomal dominant polycystic kidney disease through targeting CDKN1C. All those previous studies suggest that miR-199a-5p might be a novel target for treatment of various diseases. Our study, for the first time, showed that miR-199a-5p mRNA level was significantly increased after $0 G D / R(p<0.05)$, whereas pretreatment with atorvastatin significantly reserved it $(p<0.05)$. In addition, we further showed that downregulation and upregulation of miR-199a-5p mRNA by transfection respectively increased and decreased GSK-3 $\beta$ both in mRNA and protein levels suggesting that miR-199a-5p mRNA exert its effects via GSK-3 $\beta$. It is noteworthy to mention that other microRNAs, such as miR-31[32] and miR-17[33], have also been found to be involved in cardiac ischemia/reperfusion injury. 


\section{Cellular Physiology Cell Physiol Biochem 2016;39:1021-1030 \begin{tabular}{ll|l}
\hline and Biochemistry $10.1159 / 000447809$ & $\begin{array}{l}\text { Published on } 2016 \text { The Author(s). Published by S. Karger AG, Basel } \\
\text { www.karger.com/cpb }\end{array}$ \\
\hline
\end{tabular}

In conclusion, our study suggests a potential mechanism of this helpful effect in which atorvastatin attenuates $\mathrm{OGD} / \mathrm{R}$-induced apoptosis in cardiomyocytes by upregulating specific survival proteins such as GSK-3 $\beta$ via downregulation of miR-199a-5p. For the first tem, our data provide new insight into the mechanisms underlying the effectiveness of atorvastatin in reducing apoptosis in myocardial I/R injury. Statins is a standard ingredient of the therapeutic regimen in hypercholesterolemia. Recently, it was found to prevent cardiovascular diseases, although the exact mechanism remains unclear. The results presented here demonstrated that atorvastatin increases the cardioprotective effects of GSK-3 $\beta$ by inhibiting miR-199a-5p.

\section{Disclosure Statement}

The authors declared that there is no conflict of interests.

\section{References}

1 Wong ND: Epidemiological studies of CHD and the evolution of preventive cardiology. Nat Rev Cardiol 2014;11:276-289.

-2 Prasad A, Stone GW, Holmes DR, Gersh B: Reperfusion injury, microvascular dysfunction, and cardioprotection: the "dark side" of reperfusion. Circulation 2009;120:2105-2112.

3 Gottlieb RA, Burleson KO, Kloner RA, Babior BM, Engler RL: Reperfusion injury induces apoptosis in rabbit cardiomyocytes. J Clin Invest 1994;94:1621-1628.

4 Saraste A, Pulkki K, Kallajoki M, Henriksen K, Parvinen M, Voipio-Pulkki LM: Apoptosis in human acute myocardial infarction. Circulation 1997;95:320-323.

5 Freude B, Masters TN, Robicsek F, Fokin A, Kostin S, Zimmermann R, Ullmann C, Lorenz-Meyer S, Schaper $\mathrm{J}$ : Apoptosis is initiated by myocardial ischemia and executed during reperfusion. J Mol Cell Cardiol 2000;32:197-208.

6 Miura T, Miki T: GSK-3beta, a therapeutic target for cardiomyocyte protection. Circ J 2009;73:1184-1192.

$>7$ Juhaszova M, Zorov DB, Yaniv Y, Nuss HB, Wang S, Sollott SJ: Role of glycogen synthase kinase-3 beta in cardioprotection. Circ Res 2009;104:1240-1252.

8 Lal H, Ahmad F, Woodgett J, Force T: The GSK-3 family as therapeutic target for myocardial diseases. Circ Res 2015;116:138-149.

-9 Xie Q, Sun Z, Chen M, Zhong Q, Yang T, Yi J: IL-8 up-regulates proliferative angiogenesis in ischemic myocardium in rabbits through phosphorylation of Akt/GSK-3 $\beta$ (ser9) dependent pathways. Int J Clin Exp Med 2015;8:12498-12508.

10 Mokhtari B, Badalzadeh R, Alihemmati A, Mohammadi M: Phosphorylation of GSK-3 $\beta$ and reduction of apoptosis as targets of troxerutin effect on reperfusion injury of diabetic myocardium. Eur J Pharmacol 2015;765:316-321.

11 Lai EC: Micro RNAs are complementary to 3' UTR sequence motifs that mediate negative posttranscriptional regulation. Nat Genet 2002;30:363-364.

12 Bartel DP: MicroRNAs: genomics, biogenesis, mechanism, and function. Cell 2004;116:281-297.

13 Chiang DY, Zhang M, Voigt N, Alsina KM, Jakob H, Martin JF, Dobrev D, Wehrens XH, Li N: Identification of microRNA-mRNA dysregulations in paroxysmal atrial fibrillation. Int J Cardiol 2015;184:190-197.

-14 Haghikia A, Missol-Kolka E, Tsikas D, Venturini L, Brundiers S, Castoldi M, Muckenthaler MU, Eder M, Stapel B, Thum T, Haghikia A, Petrasch-Parwez E, Drexler H, Hilfiker-Kleiner D, Scherr M: Signal transducer and activator of transcription 3-mediated regulation of miR-199a-5p links cardiomyocyte and endothelial cell function in the heart: a key role for ubiquitin-conjugating enzymes. Eur Heart J 2011;32:1287-1297.

15 Chen MS, Xu FP, Wang YZ, Zhang GP, Yi Q, Zhang HQ Luo JD: Statins initiated after hypertrophy inhibit oxidative stress and prevent heart failure in rats with aortic stenosis. J Mol Cell Cardiol 2004;37:889-896.

16 Ostadal P, Alan D, Hajek P, Vejvoda J, Mates M, Blasko P, Veselka J, Kvapil M, Kettner J, Wiendl M, Aschermann O, Slaby J, Nemecek E, Holm F, Rac M, Macek M, Cepova J: Fluvastatin in the therapy of acute coronary syndrome: Rationale and design of a multicenter, randomized, double-blind, placebo-controlled trial (The FACS Trial) [ISRCTN81331696] . Curr Control Trials Cardiovasc Med 2005;6:4. 


\section{Cellular Physiology Cell Physiol Biochem 2016;39:1021-1030 \begin{tabular}{l|l|l} 
DOI: 10.1159/000447809 & and Biochemistry Publisned online: August 19, 2016 & $\begin{array}{l}\text { O 2016 The Author(s). Published by S. Karger AG, Basel } \\
\text { www.karger.com/cpb }\end{array}$
\end{tabular}

17 Kapur NK, Musunuru K: Clinical efficacy and safety of statins in managing cardiovascular risk. Vasc Health Risk Manag 2008;4:341-353.

18 Di Napoli P, Taccardi AA, Grilli A, De Lutiis MA, Barsotti A, Felaco M, De Caterina R: Chronic treatment with rosuvastatin modulates nitric oxide synthase expression and reduces ischemia-reperfusion injury in rat hearts. Cardiovasc Res 2005;66:462-471.

-19 Balakumar P, Mahadevan N: Interplay between statins and PPARs in improving cardiovascular outcomes: a double-edged sword? Br J Pharmacol 2012;165:373-379.

-20 Louch WE, Sheehan KA, Wolska BM: Methods in cardiomyocyte isolation, culture, and gene transfer. J Mol Cell Cardiol 2011;51:288-298.

-21 Takeda T, Akao M, Matsumoto-Ida M, Kato M, Takenaka H, Kihara Y, Kume T, Akaike A, Kita T: Serofendic acid, a novel substance extracted from fetal calf serum, protects against oxidative stress in neonatal rat cardiac myocytes. J Am Coll Cardiol 2006;47:1882-1890.

-22 Zhao Z, Cui W, Zhang H, Gao H, Li X, Wang Y, Hu H, Li B: Pre-treatment of a single high-dose of atorvastatin providedcardioprotection in different ischemia/reperfusion models via activating mitochondrial KATP channel. Eur J Pharmacol 2015;751:89-98.

-23 Lu JC, Cui W, Zhang HL, Liu F, Han M, Liu DM, Yin HN, Zhang K, Du J: Additive beneficial effects of amlodipine and atorvastatin in reversing advanced cardiac hypertrophy in elderly spontaneously hypertensive rats. Clin Exp Pharmacol Physiol 2009;36:1110-1119.

24 Liu D, Cui W, Liu B, Hu H, Liu J, Xie R, Yang X, Gu G, Zhang J, Zheng H: Atorvastatin protects vascular smooth muscle cells from TGF- $\beta 1$-stimulated calcification by inducing autophagy via suppression of the $\beta$-catenin pathway. Cell Physiol Biochem 2014;33:129-141.

-25 Ali A, Hoeflich KP, Woodgett JR: Glycogen synthase kinase-3: properties, functions, and regulation. Chemical Reviews 2001;101:2527-2540.

-26 Sugden PH, Fuller SJ, Weiss SC, Clerk AC: Glycogen synthase kinase 3 (GSK3) in the heart: a point of integration in hypertrophic signalling and a therapeutic target? A critical analysis. $\mathrm{Br} \mathrm{J}$ Pharmacol 2008;153:S137-S153.

-27 Mora A, Sakamoto K, McManus EJ, Alessi DR: Role of the PDK1-PKB-GSK3 pathway in regulating glycogen synthase and glucose uptake in the heart. FEBS Letters 2005;579:3632-3638.

28 Latronico MV and Condorelli G: MicroRNAs and cardiac pathology. Nat Rev Cardiol 2009;6:419-429.

29 Rane S, He M, Sayed D, Vashistha H, Malhotra A, Sadoshima J, Vatner DE, Vatner SF, Abdellatif M: Downregulation of miR-199a derepresses hypoxia-inducible factor-1alpha and Sirtuin 1 and recapitulates hypoxia preconditioning in cardiac myocytes. Circ Res 2009;1047:879-886.

-30 Wang H, Gao H, Duan S, Song X: Inhibition of microRNA-199a-5p reduces the replication of HCV via regulating the pro-survival pathway. Virus Res 2015;208:7-12.

-31 Sun L, Zhu J, Wu M, Sun H, Zhou C, Fu L, Xu C, Mei C: Inhibition of MiR-199a-5p reduced cell proliferation in autosomal dominant polycystic kidney disease through targeting CDKN1C. Med Sci Monit 2015;21:195200.

32 Wang Y, Men M, Yang W, Zheng H, Xue S: MiR-31 Downregulation Protects Against Cardiac Ischemia/ Reperfusion Injury by Targeting Protein Kinase C Epsilon (PKC $)$ ) Directly. Cell Physiol Biochem 2015;36:179-190.

33 Du W, Pan Z, Chen X, Wang L, Zhang Y, Li S, Liang H, Xu C, Zhang Y, Wu Y, Shan H, Lu Y: By targeting Stat3 microRNA-17-5p promotes cardiomyocyte apoptosis in response to ischemia followed by reperfusion. Cell Physiol Biochem 2014;34:955-965. 
$* * *$

In the article by Zuo et al., entitled "Atorvastatin Protects Myocardium against IschemiaReperfusion Injury through Inhibiting miR-199a-5p" [Cell Physiol Biochem 2016;39:10211030 (DOI: 10.1159/00044780)] there are a few mistakes:

- In page 1022, the second to the last line “...for an additional $18 \mathrm{~h}, . .$. " should be changed to "...for an additional $1 \mathrm{~h}, \ldots$

- The legend of Figure 6 is wrong and should be changed into:

Fig. 6. Effects of Atorvastatin on neonatal rat cardiac ventricular cardiomyocytes viability, LDH release, and expression of Caspase 9, Bcl-2, and Cyto C. A. Images showing the verification of neonatal rat cardiac ventricular cardiomyocytes; B. Graph showing cell viability in the three groups; C. The level of Caspase 9, Bcl-2, Cyto C, and GSK-3 $\beta$ proteins in the three groups; D. Graph showing GSK-3 $\beta$ mRNA level in the three groups. E. Graph showing miR- 199a-5p mRNA level in the three groups; F. Graph showing LDH release in the five groups; G. The level of Caspase $9, \mathrm{Bcl}-2$, and Cyto $\mathrm{C}$ proteins in the five groups. ${ }^{*}$ compared with the control group, $\mathrm{p}<0.05$. \# compared with the OGD/R group, $\mathrm{p}<0.05$.

The authors sincerely apologize for the errors. 